\title{
Biomechanical comparison of semirigid junctional fixation techniques to prevent proximal junctional failure after thoracolumbar adult spinal deformity correction
}

Citation for published version (APA):

Doodkorte, R. J. P., Roth, A. K., Arts, J. J., Lataster, L. M. A., van Rhijn, L. W., \& Willems, P. C. (2021). Biomechanical comparison of semirigid junctional fixation techniques to prevent proximal junctional failure after thoracolumbar adult spinal deformity correction. The Spine Journal, 21(5), 855-864. https://doi.org/10.1016/j.spinee.2021.01.017

Document status and date:

Published: 01/05/2021

DOI:

10.1016/j.spinee.2021.01.017

Document Version:

Publisher's PDF, also known as Version of record

Document license:

Taverne

Please check the document version of this publication:

- A submitted manuscript is the version of the article upon submission and before peer-review. There can be important differences between the submitted version and the official published version of record. People interested in the research are advised to contact the author for the final version of the publication, or visit the DOI to the publisher's website.

- The final author version and the galley proof are versions of the publication after peer review.

- The final published version features the final layout of the paper including the volume, issue and page numbers.

Link to publication

\footnotetext{
General rights rights.

- You may freely distribute the URL identifying the publication in the public portal. please follow below link for the End User Agreement:

www.umlib.nl/taverne-license

Take down policy

If you believe that this document breaches copyright please contact us at:

repository@maastrichtuniversity.nl

providing details and we will investigate your claim.
}

Copyright and moral rights for the publications made accessible in the public portal are retained by the authors and/or other copyright owners and it is a condition of accessing publications that users recognise and abide by the legal requirements associated with these

- Users may download and print one copy of any publication from the public portal for the purpose of private study or research.

- You may not further distribute the material or use it for any profit-making activity or commercial gain

If the publication is distributed under the terms of Article 25fa of the Dutch Copyright Act, indicated by the "Taverne" license above, 


\title{
Biomechanical comparison of semirigid junctional fixation techniques to prevent proximal junctional failure after thoracolumbar adult spinal deformity correction
}

\author{
Remco J.P. Doodkorte, MSc ${ }^{\mathrm{a}, *}$, Alex K. Roth, PhD ${ }^{\mathrm{a}}$, Jacobus J. Arts, PhD ${ }^{\mathrm{a}}$, \\ L.M. Arno Lataster, MSc, MEd ${ }^{\mathrm{b}}$, Lodewijk W. van Rhijn, MD, $\mathrm{PhD}^{\mathrm{a}}$, \\ Paul C. Willems, MD, PhD ${ }^{\mathrm{a}}$ \\ ${ }^{a}$ Department of Orthopedic Surgery, Research School CAPHRI, Maastricht University Medical Center, P. Debyelaan 25, 6229 \\ HX, Maastricht, The Netherlands \\ ${ }^{\mathrm{b}}$ Department of Anatomy and Embryology, Faculty of Health, Medicine and Life Sciences, Maastricht University Medical \\ Center, P. Debyelaan 25, 6229 HX, Maastricht, The Netherlands \\ Received 30 October 2020; revised 8 January 2021; accepted 18 January 2021
}

Abstract

BACKGROUND CONTEXT: Adult spinal deformity patients treated operatively by longsegment instrumented spinal fusion are prone to develop proximal junctional kyphosis (PJK) and failure (PJF). A gradual transition in range of motion (ROM) at the proximal end of spinal instrumentation may reduce the incidence of PJK and PJF, however, previously evaluated techniques have not directly been compared.

PURPOSE: To determine the biomechanical characteristics of five different posterior spinal instrumentation techniques to achieve semirigid junctional fixation, or "topping-off," between the rigid pedicle screw fixation (PSF) and the proximal uninstrumented spine.

STUDY DESIGN: Biomechanical cadaveric study.

METHODS: Seven fresh-frozen human cadaveric spine segments (T8-L3) were subjected to ex vivo pure moment loading in flexion-extension, lateral bending and axial rotation up to $5 \mathrm{Nm}$. The native condition, three-level PSF (T11-L2), PSF with supplemental transverse process hooks at T10 (TPH), and two sublaminar taping techniques (knotted and clamped) as one- (T10) or twolevel (T9, T10) semirigid junctional fixation techniques were compared. The ROM and neutral zone (NZ) of the segments were normalized to the native condition. The linearity of the transition zones over three or four segments was determined through linear regression analysis.

RESULTS: All techniques achieved a significantly reduced ROM at T10-T11 in flexion-extension and axial rotation relative to the PSF condition. Additionally, both two-level sublaminar taping techniques (CT2, KT2) had a significantly reduced ROM at T9-T10. One-level clamped sublaminar tape (CT1) had a significantly lower ROM and NZ compared with one-level knotted sublaminar tape (KT1) at T10-T11. Linear regression analysis showed the highest linear correlation between ROM and vertebral level for TPH and the lowest linear correlation for CT2.

CONCLUSIONS: All studied semirigid junctional fixation techniques significantly reduced the ROM at the junctional levels and thus provide a more gradual transition than pedicle screws. TPH achieves the most linear transition over three vertebrae, whereas KT2 achieves that over four vertebrae. In contrast, CT2 effectively is a one-level semirigid junctional fixation technique with a shift in the upper rigid fixation level. Clamped sublaminar tape reduces the NZ greatly, whereas knotted

FDA device/drug status: Approved (Transverse process hooks, Universal Clamp, Zimmer), Not approved (Knotted sublaminar tape).

Author disclosures: RJPD: Grant: Chemelot inSciTe Project BM2.02 Posture (H). AKR: Grant: Chemelot inSciTe Project BM2.02 Posture (H). JJA: Grant: Chemelot inSciTe Project BM2.02 Posture (H). LMAT: Grant: Chemelot inSciTe Project BM2.02 Posture (H). LWVR: Nothing to disclose. PCW: Grant: Chemelot inSciTe Project BM2.02 Posture (H).

\footnotetext{
Statements: This research was performed within the Chemelot InSciTe framework and the authors have no financial or competing interests related to this work.

*Corresponding author. Maastricht University, Department of Orthopedic Surgery, Universiteitssingel 50, 6229 ER, Maastricht, The Netherlands. Tel.: +31-43-3881304; fax: +31-43-3874893.

E-mail address: rjp.doodkorte@maastrichtuniversity.nl (R.J.P. Doodkorte).
} 
sublaminar tape and TPH maintain a more physiologic NZ. Clinical validation is ultimately required to translate the biomechanics of various semirigid junctional fixation techniques into the clinical goal of reducing the incidence of proximal junctional kyphosis and failure.

CLINICAL SIGNIFICANCE: The direct biomechanical comparison of multiple instrumentation techniques that aim to reduce the incidence of PJK after thoracolumbar spinal fusion surgery provides a basis upon which clinical studies could be designed. Furthermore, the data provided in this study can be used to further analyze the biomechanical effects of the studied techniques using finite element models to better predict their post-operative effectiveness. (c) 2021 Elsevier Inc. All rights reserved.

Keywords: $\quad$ Adult spinal deformity, Biomechanics, Proximal junctional kyphosis, Proximal junctional failure; Semirigid, Topping-off

\section{Introduction}

The rates of long-segment instrumented spinal fusion as treatment for adult spinal deformity have increased dramatically in the past decade. Long-segment instrumented spinal fusion is associated with high complication and revision rates [1]. The most prevalent complication following posterior instrumented spinal fusion is proximal junctional kyphosis (PJK), which occurs in $17 \%$ to $39 \%$ of the operated patients [2,3]. PJK is defined as a post-operative increase of the proximal junctional Cobb angle greater than $10^{\circ}$ [4]. Aggravation of PJK, vertebral body fracture, loss of posterior ligament complex integrity, implant failure, or vertebral subluxation result in proximal junctional failure (PJF), which often requires revision surgery $[5,6]$. Patient specific risk factors for the development of PJK include advanced age, high body mass index, low bone mineral density, and the presence of comorbidities [7-10]. Furthermore, surgical risk factors include a combined anterior and posterior surgical approach, a larger sagittal balance correction and the upper instrumented vertebral level at the thoracolumbar junction $[11,12]$. Previously, a reduced stiffness at the proximal end of a spinal construct, semirigid junctional fixation, has been identified as a protective factor against PJK $[13,14]$. This has led to the proposal of longsegment constructs with semirigid junctional fixation at the proximal end, so-called topping-off. Semirigid junctional fixation techniques aim to create a gradual transition in range of motion (ROM) at the transition between the rigid pedicle screw construct and the uninstrumented proximal spine, which is believed to reduce peak stresses at the boneimplant interface, in the posterior ligaments and the vertebral bodies.

Both transverse process hooks (TPHs) and clamped sublaminar tapes have been assessed clinically as semirigid junctional fixation techniques. A significantly lower PJK incidence was found for TPH constructs in comparison to all pedicle screw constructs in both a retrospective clinical study and a matched cohort $[15,16]$. Also, Line et al. found significant lower PJF incidence rates for treated patients treated with TPH constructs compared with pedicle screw fixation (PSF) [16]. Alternatively, the feasibility of onelevel sublaminar tape in adjunct to posterior PSF was demonstrated by the absence of any PJF case 12 months postoperatively in an uncontrolled cohort study with 40 adult spinal deformity patients [17]. Besides clinically, TPH and clamped sublaminar tape have also been evaluated biomechanically as semirigid junctional fixation techniques [15,16,18-20]. TPHs have been demonstrated to provide a gradual transition in ROM across junctional segments. However, this was only demonstrated in porcine specimens, which hampers comparison to other techniques [21,22]. One- and two-level clamped sublaminar tape as a semirigid junctional fixation technique also demonstrated to reduce the ROM at the junctional zone in human cadaveric spine segments $[20,23]$. However, two-level junctional fixation with clamped sublaminar tapes did not result in a gradual ROM transition over both levels but primarily at the most proximal level. Alternatively, knotted sublaminar tape has previously been studied as a nonrigid dynamic stabilization system to prevent adjacent segment disease following lumbar fusion surgery, and may also be considered as a semirigid junctional fixation technique [24,25]. We hypothesize that the unconstrained longitudinal sliding of knotted sublaminar tape results in a higher ROM at the junctional segments in comparison to clamped sublaminar tape [26,27]. In addition, we hypothesize that this unconstrained longitudinal sliding will allow for extension of the junctional zone over multiple levels, which theoretically distributes stress over a greater number of vertebrae, thus reducing peak stress levels.

Clinical investigations on the application of various semirigid instrumentation techniques aiming to reduce PJK and PJF are predominantly of retrospective nature and lack side-by-side comparison. Therefore, the objective of this study is to compare different semirigid means of extending the junctional zone in a quasi-static human cadaveric biomechanical experiment.

\section{Methods}

\section{Specimens}

Seven fresh-frozen human thoracolumbar spine segments (T8-L3) were included in this study (three male, four female), with an average donor age of 83.1 years (range 69-94). The specimens were obtained from donors 
who donated their bodies to the Department of Anatomy and Embryology, Faculty of Health, Medicine and Life Sciences, Maastricht University, Maastricht, the Netherlands for the purpose of scientific research and education. A handwritten and signed codicil was received from all donors and is kept at this department. The mean bone mineral density of the excised spines was measured using dual energy Xray absorptiometry (DEXA) (Discovery W; Hologic Inc., Marlborough, MA, USA). Intervertebral disc degeneration was graded using the Modified Pfirrmann grading scale (1-8) based on 1.5-T T2-weighted MRI images (Achieva, Philips, Best, the Netherlands) [28]. Specimen with gross anatomical anomalies, such as deformities and fractures, were excluded.

The specimens $\left(-30^{\circ} \mathrm{C}\right)$ were thawed at room temperature under running tap-water before MRI scanning. Posterior paravertebral musculature and the psoas muscles were removed while care was taken to preserve ligamentous structures. The cleaned spinal columns were wrapped in phosphate buffered saline soaked gauze, refrozen, and thawed at $4^{\circ} \mathrm{C}$ overnight before testing. Four standard woodscrews were introduced into the cranial and caudal endplate of T8 and L3 vertebra respectively, before embedding in poly methyl methacrylate resin (Technovit 3040; Heraeus Kulzer GmbH, Wehrheim, Germany). A line laser was used for optimal alignment in the three anatomical planes. The specimens were kept soaked using phosphate buffered saline throughout the experiment.

\section{Testing conditions}

Each spine was tested in seven conditions; the native, three-level bilateral PSF, and five different semi-rigid junctional fixation conditions (in addition to the PSF). The test sequence was as follows (Fig. 1):

1. Native: The intact spine was tested to assess normal ROM before instrumentation.

2. Three-level PSF: Eight poly-axial pedicle screws were inserted using the freehand technique at $\mathrm{T} 11-\mathrm{L} 2$ and segments were bilaterally fixated with $\varnothing 5.5-\mathrm{mm}$ titanium rods (CD Horizon, Medtronic Sofamor Danek, Memphis, USA).

3. TPH: The cranial edge of the T10 transverse processes were revealed using a scalpel, and wide blade hooks (CD Horizon Solera, Medtronic Sofamor Danek, Memphis, USA) were bilaterally placed supplemental to the PSF at T11-L2. Segments were subsequently fixated with $\varnothing 5.5 \mathrm{~mm}$ titanium rods.

4. One-level sublaminar tape with clamp (CT1): The cranial and caudal flaval ligament of T10 was removed before bilateral sublaminar tape (Universal clamp; Zimmer Spine, SAS, Bordeaux, France) passage. Care was taken to keep spinous processes and inter-/supraspinal ligaments intact. After fixation of the pedicle screws to the rod, the tape was tensioned according to manufacturer's instructions $(700 \mathrm{~N})$ and the clamp was fixated to the rod using the set screw.

5. One-level sublaminar tape knotted (KT1): The clamped sublaminar tapes at T10 were replaced with $4 \mathrm{~mm}$ wide ultra-high molecular weight polyethylene sublaminar tapes (made with Dyneema Purity Radiopaque fibers; DSM Biomedical, Geleen, the Netherlands). After securing the cable around the rod with a double-loop Klemheist knot and a single throw square knot, the tape
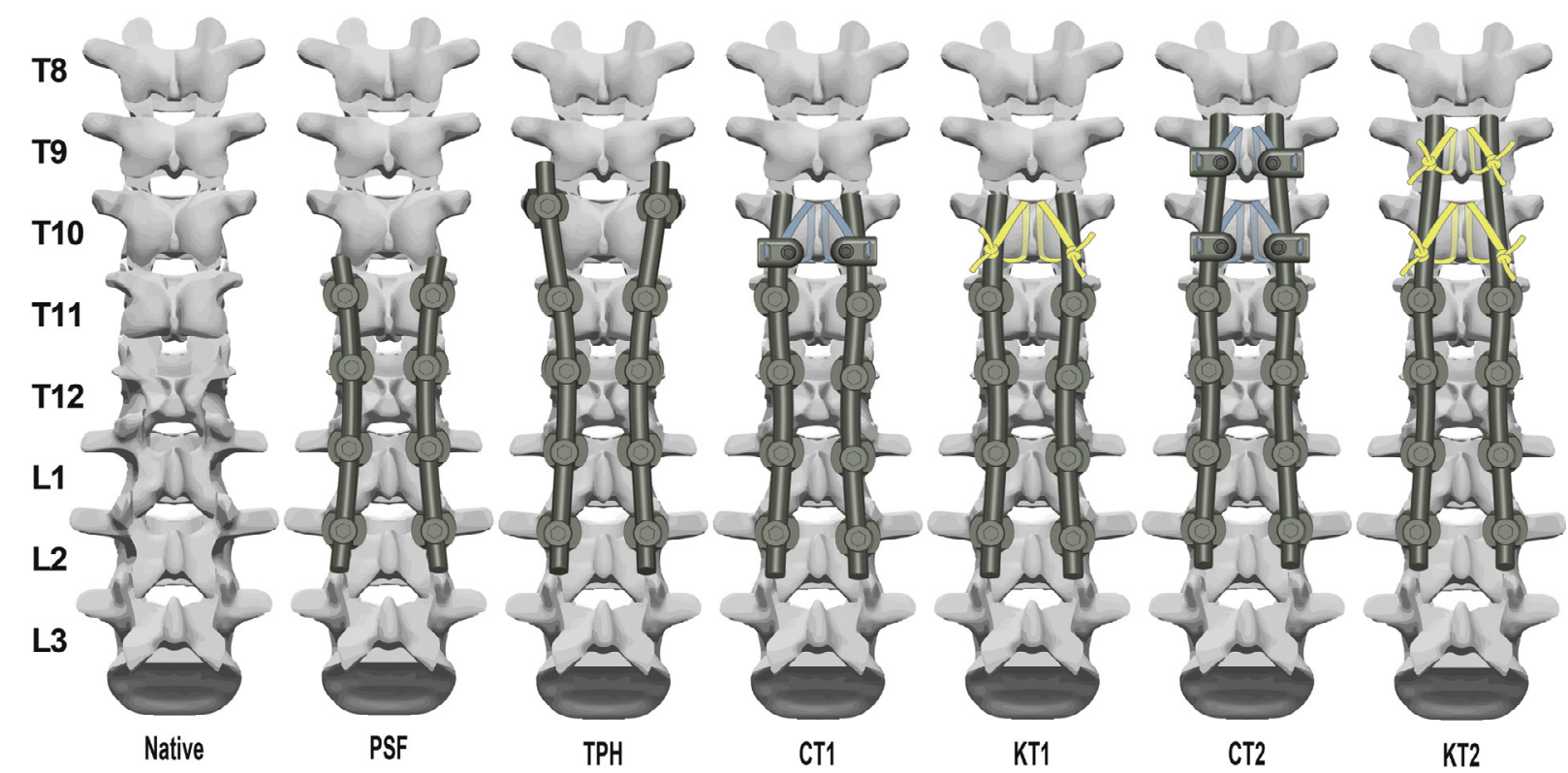

Fig. 1. Definitions and illustrations of the experimental conditions. PSF,3 level pedicle screw fixation; TPHs, 3 level pedicle screw fixation +1 level transverse process hooks; CT1,3 level pedicle screw fixation +1 level clamped sublaminar tape; KT1,3 level pedicle screw fixation +1 level knotted sublaminar tape; CT2,3 level pedicle screw fixation +2 level clamped sublaminar tape; KT2,3 level pedicle screw fixation + 2 level knotted sublaminar tape. 
was tensioned up to $500 \mathrm{~N}$ using a custom tensioning device. The knots were finally secured through an additional six reversed half-hitches on alternating posts [29].

6. Two-level sublaminar tape with clamp (CT2): The flaval ligament proximal to T9 was removed and four clamped sublaminar tapes were passed at the T10 and T9 levels. Again, care was taken to keep the posterior elements and ligaments intact. After fixation of the pedicle screws to the rod, the tapes were tensioned and clamps were fixated according to manufacturer's instructions.

7. Two-level sublaminar tape knotted (KT2): Analogous to CT2, two levels of knotted UHMWPE sublaminar tape were fixated at T10 and T9.

After conditions 3, 5, and 7, all instrumentation was removed (except for the pedicle screws) and the spine was subjected to the same biomechanical testing regime to assess the effect of ligament resection.

\section{Biomechanical testing}

The specimen were tested in the three principal directions; flexion-extension, lateral bending and axial rotation using an electronic 6-degree of freedom spine testing system capable of applying unconstrained pure moments (FS21; Applied Test Systems, Buttler, PA, USA) [30]. For each condition, the specimen was loaded at $1 \%$ sec for 5 cycles from -5 to $5 \mathrm{Nm}$ in each of the principle directions. Individual vertebrae were tracked by LED-marker triplets using an optical registration system (Optotrak Certus, Northern Digital, Waterloo, Ontario, Canada) and the data was synchronously collected by the spine tester software.

\section{Data and statistical analysis}

Individual segment rotations were calculated using a custom-written algorithm (Matlab R2017b, MathWorks, Natick, MA, USA) and the ROM of the fourth cycle was determined in each principle direction. The rotational and translation freedom of semirigid junctional fixation techniques may also be reflected into the neutral zone (NZ). The NZ is the unforced rotation around the neutral position of the spine during which no additional stresses are exerted on the instrumentation. Therefore, the magnitude of the NZ was determined by curve fitting the moment-rotation curves of the index (T10-T11) and index+1 segments (T9-T10) (Fig. 2) to a summed sigmoid function [31]. ROM and NZ data was normalized to the intact condition to account for interspecimen differences.

Statistical analysis was performed using SPSS statistics software (SPSS 25; IBM, Chicago, IL, USA). Normalized ROMs were analyzed at the semirigid fixation levels (index and index+1) using one-way ANOVA tests comparing the

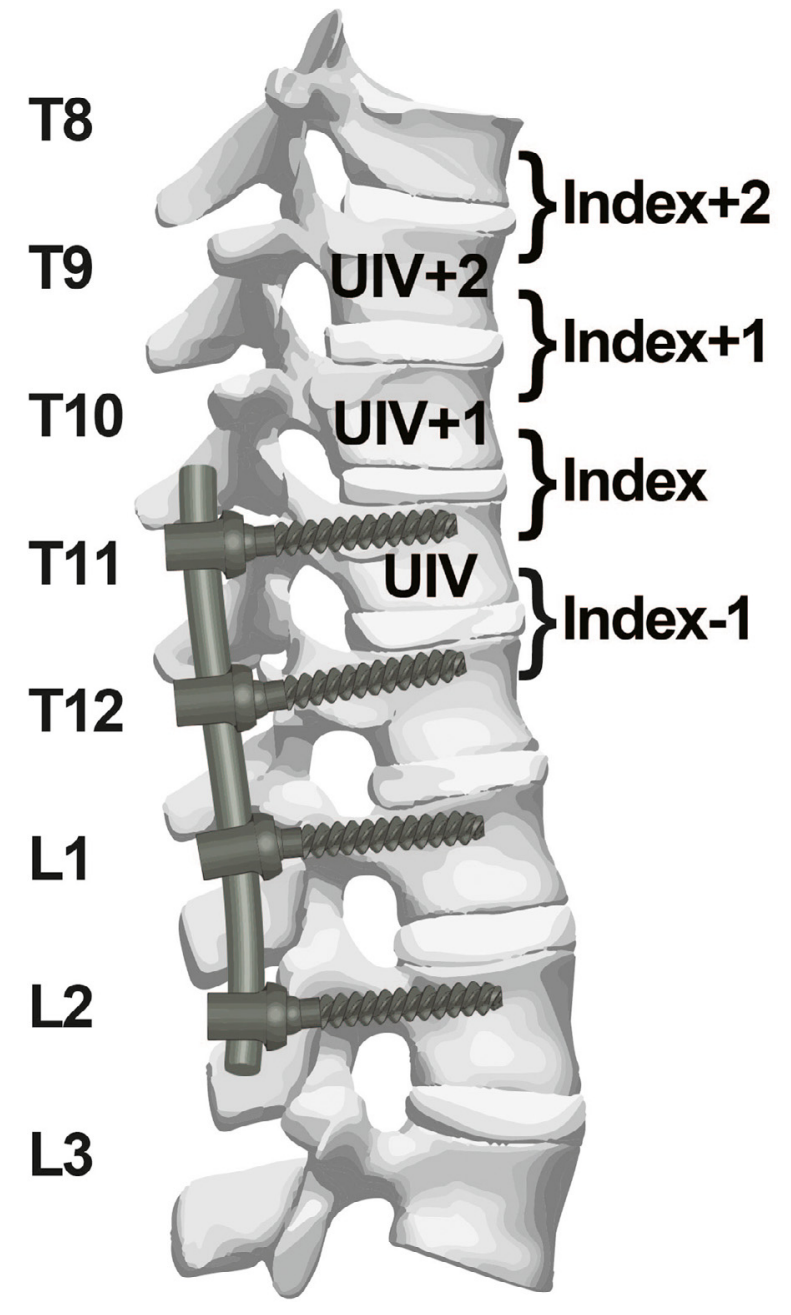

Fig. 2. The upper instrumented vertebra (UIV) is defined as the most proximal pedicle screw fixation. Relative rotation of the UIV- UIV+1

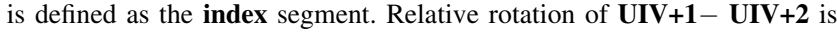
defined as the index+1 segment.

ROM at each individual level for each of the seven conditions. Bonferroni correction for multiple comparisons was used and statistical significance was set at $\mathrm{p}<.05$. The normalized NZs were only compared in flexion-extension using the same tests.

A linear regression analysis was performed across the junctional zones in flexion-extension to compare the increase in ROM across the junctional zones. For this analysis, the ROM of the most proximal rigid fixation (index1) up to the first non-instrumented segment (index +1 or index +2 ) is fitted to a linear relation (Fig. 2). Index +2 was only included for two-level semi-rigid fixation compared with PSF. Rotations at the index-1 segment, the intercept, was set at 0 for "no rotation." Linearity is expressed through the R-squared value for which an R-squared value approaching 1.00 indicates a higher linear correlation and therefore, a more gradual increase of ROM over the junctional levels. 


\section{Results}

\section{Specimens and test characteristics}

The specimens' average bone mineral density was $0.609 \pm 0.098 \mathrm{~g} / \mathrm{cm}^{2}$ and the intervertebral discs had an average degeneration grade of $3.6 \pm 0.990$ (Specimen and segment specific values: Supplemental Table A.1). All tests were completed successfully.

\section{ROM analysis}

Normalized ROMs are displayed in Fig. 3 and pair-wise comparison of the $\mathrm{p}$-values between each technique at both the index and index +1 level can be found in Table 1 (Mean and Standard deviation for all levels in each condition:
Supplemental Table A.2). In flexion-extension and axial rotation, all topping-off fixation techniques exhibited a significantly reduced ROM at the index segment relative to PSF. The CT2 and KT2 group exhibited a significantly reduced $\mathrm{ROM}$ at the index +1 segment compared with all single level semirigid junctional fixation techniques in flexion-extension and axial rotation.

Specifically comparing one-level semirigid junctional fixation techniques amongst each other, a significant difference was only observed between CT1 $(0.303 \pm 0.166)$ and KT1 $(0.674 \pm 0.202)$ in flexion-extension ROM at the index level ( $\mathrm{p}=.001$ ). Pairwise comparison between the two-level semirigid junctional fixations, CT2 and KT2, did not demonstrate any significant differences in ROM at either the index or index +1 segment.

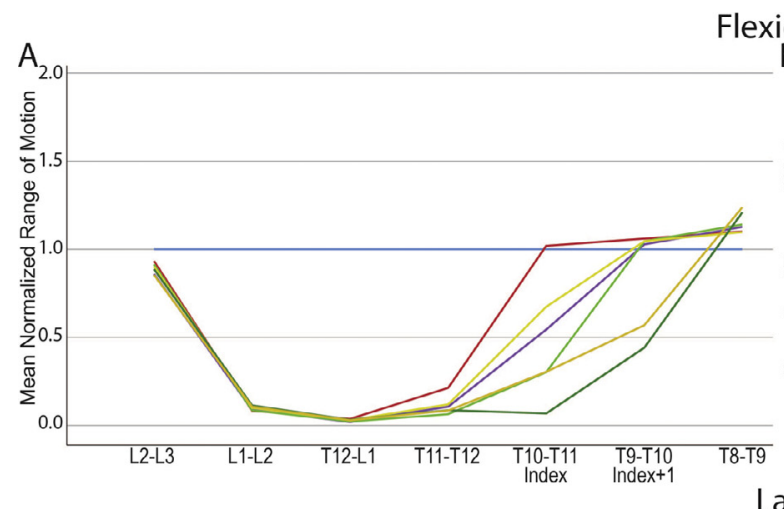

Flexion-Extension
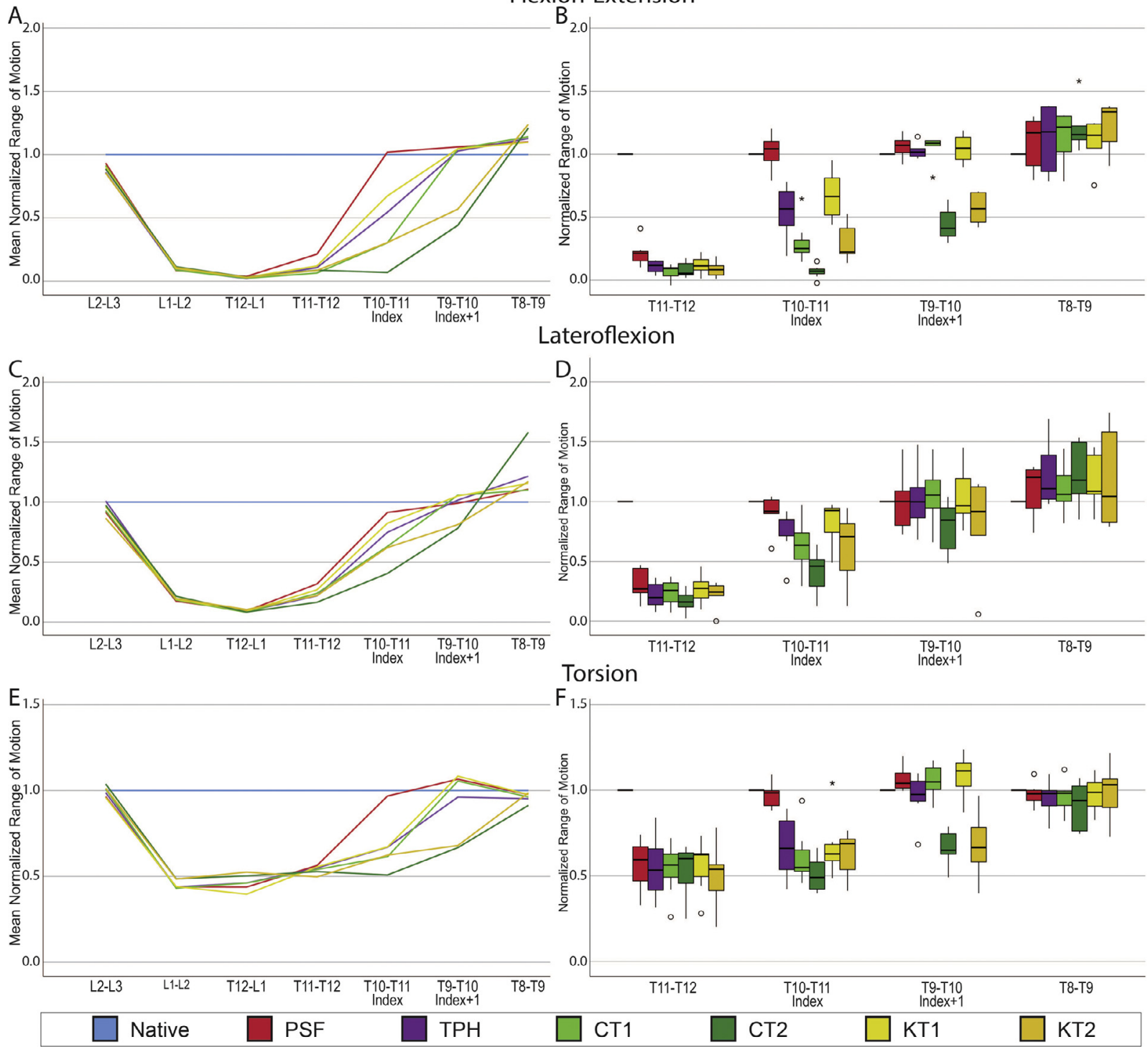

Fig. 3. Normalized range of motion in flexion-extension (A, B), lateral bending (C, D) and axial rotation (E, F). Line graphs indicate mean normalized range of motion over the complete experimented spine segments (A, C, E). Boxplots indicate median, interquartile range of proximal fixation level T11-T12 up to the uninstrumented T8-T9 level (B, D, F). PSF, 3 level pedicle screw fixation; TPH, transverse process hook; CT1, 1 level sublaminar tape clamp; CT2, 2 level sublaminar tape clamp; KT1, 1 level sublaminar tape knot; KT2, 2 level sublaminar tape knot. 
Table 1.

Pairwise $p$-values of index and index +1 level between all conditions

\begin{tabular}{|c|c|c|c|c|c|c|}
\hline \multicolumn{7}{|c|}{ Flexion-Extension } \\
\hline & PSF & TPH & CT1 & $\mathrm{CT} 2$ & KT1 & KT2 \\
\hline PSF & - & 1.000 & 1.000 & $<0.001^{*}$ & 1.000 & $<0.001^{*}$ \\
\hline TPH & $<0.001^{*}$ & - & 1.000 & $<0.001^{*}$ & 1.000 & $<0.001^{*}$ \\
\hline CT1 & $<0.001^{*}$ & 0.090 & - & $<0.001^{*}$ & 1.000 & $<0.001^{*}$ \\
\hline $\mathrm{CT} 2$ & $<0.001^{*}$ & $<0.001^{*}$ & 0.115 & - & $<0.001^{*}$ & 0.677 \\
\hline KT1 & $0.002^{*}$ & 1.000 & $0.001^{*}$ & $<0.001^{*}$ & - & $<0.001^{*}$ \\
\hline KT2 & $<0.001^{*}$ & 0.096 & 1.000 & 0.107 & $0.001^{*}$ & - \\
\hline \multicolumn{7}{|c|}{ Lateral bending } \\
\hline & PSF & TPH & CT1 & $\mathrm{CT} 2$ & KT1 & KT2 \\
\hline PSF & - & 1.000 & 1.000 & 1.000 & 1.000 & 1.000 \\
\hline TPH & 1.000 & - & 1.000 & 1.000 & 1.000 & 1.000 \\
\hline CT1 & 0.195 & 1.000 & - & 1.000 & 1.000 & 1.000 \\
\hline $\mathrm{CT} 2$ & $<0.001^{*}$ & $0.041^{*}$ & 0.742 & - & 1.000 & 1.000 \\
\hline KT1 & 1.000 & 1.000 & 1.000 & $0.005^{*}$ & - & 1.000 \\
\hline KT2 & 0.204 & 1.000 & 1.000 & 1.000 & 1.000 & - \\
\hline \multicolumn{7}{|c|}{ Axial rotation } \\
\hline & PSF & $\mathrm{TPH}$ & $\mathrm{CT} 1$ & $\mathrm{CT} 2$ & KT1 & KT2 \\
\hline PSF & - & 1.000 & 1.000 & $<0.001^{*}$ & 1.000 & $<0.001^{*}$ \\
\hline TPH & $0.003^{*}$ & - & 1.000 & $0.001^{*}$ & 1.000 & $0.001^{*}$ \\
\hline CT1 & $<0.001^{*}$ & 1.000 & - & $<0.001^{*}$ & 1.000 & $<0.001^{*}$ \\
\hline CT2 & $<0.001^{*}$ & 0.602 & 1.000 & - & $<0.001^{*}$ & 1.000 \\
\hline KT1 & $0.003^{*}$ & 1.000 & 1.000 & 0.574 & - & $<0.001^{*}$ \\
\hline KT2 & $<0.001^{*}$ & 1.000 & 1.000 & 1.000 & 1.000 & - \\
\hline
\end{tabular}

When comparing the two knotted sublaminar tape conditions, KT1 and KT2, a significantly lower ROM in flexionextension at the index segment was observed $(\mathrm{p}=.001)$ for KT2. This difference was not observed at the index level when comparing the clamped tape conditions (CT1 and CT2) $(\mathrm{p}=.115)$. A paired-samples $t$ test revealed no difference in flexion-extension ROM between the index and index-1 segments (PSF) for CT2 fixation ( $\mathrm{p}=.972$ ).

At L2-L3, caudal to the lowest fixation level, a normal ROM was measured in all conditions. Similar ROMs were measured at the PSF instrumented levels (T11-L2) for all conditions, although the ROM reduced only to $39.6 \%$ to $56.3 \%$ along these segments in axial rotation. In lateral bending, the only significant difference compared with PSF was for CT2 at the index segment $(\mathrm{p}=.000)$.

\section{Junctional zone ROM linear regression analysis}

Linear regression of the ROM over the junctional levels from the index -1 to index +1 segments yielded higher $\mathrm{R}^{2}$ values for TPH, CT1 and KT1 $\left(\mathrm{R}^{2}=0.956,0.928\right.$ and 0.945 , respectively), as compared with PSF (index-1 to index +1
$\mathrm{R}^{2}=0.874$ ) (Table 2). The Pearson's correlation for KT2 $\left(\mathrm{R}^{2}=0.937\right)$ was higher than for CT2 $\left(\mathrm{R}^{2}=0.863\right)$ and PSF (index-1 to index $+2, \mathrm{R}^{2}=0.870$ ).

\section{$N Z$ analysis}

The normalized NZ in the CT1 and CT2 group compared with the native condition was significantly reduced at the index segment $0.166 \pm 0.103(\mathrm{p}=.001)$ and $0.029 \pm 0.033$

Table 2.

$\mathrm{R}^{2}$-values from linear regression analysis of all semirigid junctional fixation techniques

\begin{tabular}{llll}
\hline 1 level semirigid junctional zone* & \multicolumn{2}{l}{ 2 level semirigid junctional zone ${ }^{\dagger}$} \\
\hline PSF & 0.874 & PSF & 0.840 \\
CT1 & 0.928 & CT2 & 0.863 \\
KT1 & 0.945 & KT2 & 0.937 \\
TPH & 0.956 & & \\
\hline
\end{tabular}

PSF, 3 level pedicle screw fixation; CT1, 1 level sublaminar tape clamp; CT2, 2 level sublaminar tape clamp; KT1, 1 level sublaminar tape knot; KT2, 2 level sublaminar tape knot; TPH, transverse process hook.

* Linear regression from T9 to T11.

$\dagger$ Linear regression from $\mathrm{T} 8$ to $\mathrm{T} 11$. 


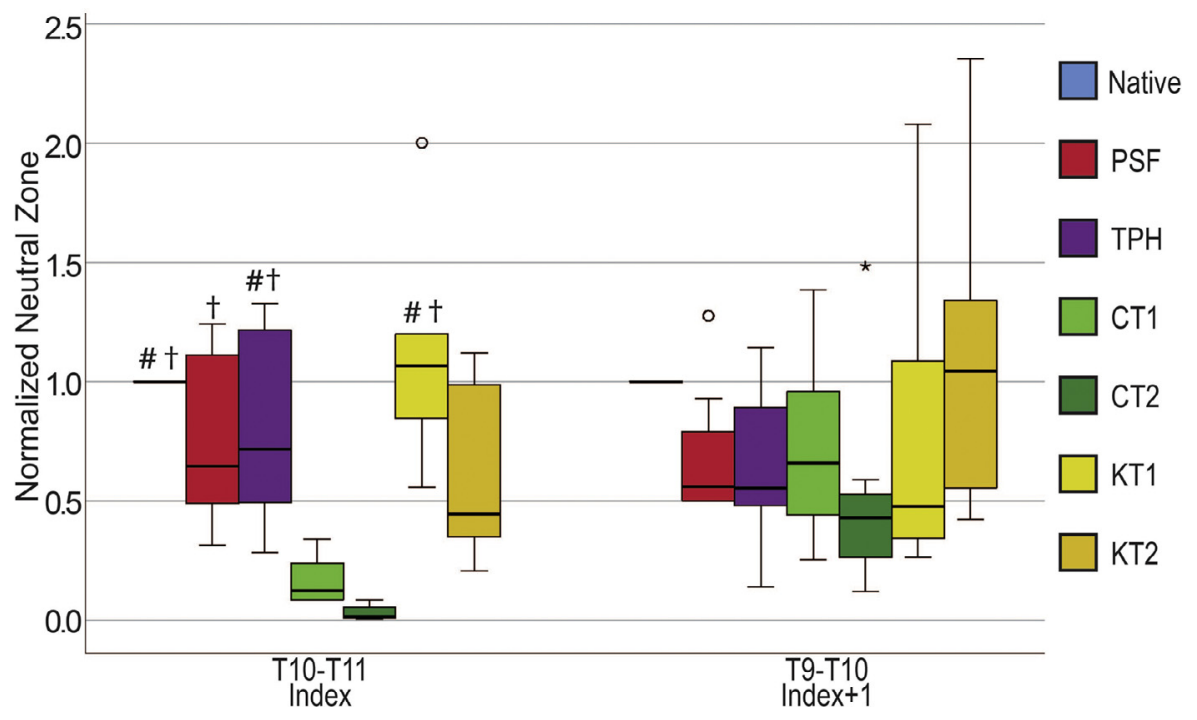

Fig. 4. Normalized neutral zones at semirigid fixation levels. $\#=p<.05$ compared to $C T 1, \dagger=p<.05$ compared to CT2.

( $\mathrm{p}=.000$ ), respectively (Fig. 4). The CT1 group had a significantly smaller NZ compared with the TPHs $(0.791 \pm 0.409$, $\mathrm{p}=.032)$ and KT1 group $(1.122 \pm 0.487, \mathrm{p}=.000)$. The CT2 group has a significantly reduced $\mathrm{NZ}$ at the index segment compared with the PSF $(0.741 \pm 0.370, \mathrm{p}=.008)$, TPH $(\mathrm{p}=.004)$, and KT1 $(\mathrm{p}=.000)$ groups. No significant difference was measured with respect to the KT2 group (0.592 \pm 0.372 ) at the index segment. No significant differences were observed at the index +1 segment for the KT2 and CT2 groups compared with the control groups.

\section{Discussion}

PJK and PJF are highly prevalent after instrumented thoracolumbar adult spinal deformity correction [1,6]. Kim et al. suggested that the abrupt change in ROM between the instrumented spine and the proximal uninstrumented spine is one of the underlying factors for the development of PJK [13]. In the current study, five different semirigid junctional fixation techniques were compared in an ex vivo biomechanical setup with human cadaveric spine segments. TPHs, one- and two-level clamped sublaminar tape, and one- and two-level knotted sublaminar tape were compared with three-level PSF. Although all techniques reduced the ROM at the index junctional segment(s), TPHs and knotted sublaminar tape achieved the most linear increase in ROM across the junctional segments for one- and two-level techniques, respectively. Effects were most pronounced in flexion-extension, but also significant for all techniques in axial rotation.

\section{$R O M$}

Previously, Viswanathan et al. performed a biomechanical study in which one- and two-level clamped sublaminar tapes as semirigid junctional fixation was compared with segmental PSF in eight vertebrae spine segment [20]. The present study demonstrated similar results for the one- and two-level semirigid junctional fixation with clamped sublaminar tapes. Besides a significantly reduced ROM at the index segment for one-level clamped sublaminar tape, twolevel sublaminar tape does not provide the most linear transition in flexion-extension ROM across the junctional zone. The similar ROM at the index-1 level (PSF) compared with the index level (distal CT) for the CT2 group suggest that using clamped sublaminar tapes over multiple levels effectively results in rigid fixation similar to PSF at the index level. In other words, an additional level of clamped sublaminar tape does not broaden the transition zone, but only shifts it up one level. In this respect, the knotted sublaminar tape significantly differs from the clamped sublaminar tape. As hypothesized, the one-level knotted sublaminar tape exhibited a significantly higher ROM compared with the clamped sublaminar tape at the index level, while still reducing the ROM compared with PSF in a magnitude similar to TPH semirigid junctional fixation.

The biomechanics of a construct with TPHs at the proximal end has previously been compared biomechanically to a segmental pedicle screw constructs in two cadaveric porcine studies. Both studies demonstrated the potential to achieve a gradual transition in ROM using TPH at the proximal end [21,22]. The present study confirms these results using human cadaveric spinal segments demonstrating the clear rationale for using TPH as semirigid junctional fixation. However, in parallel to the reduction of bone mineral density in the anterior column, the posterior elements are also affected by the aging process. And among the posterior elements, the transverse processes are more affected than the lamina [32]. Therefore, patient specific considerations should be taken when considering TPHs as a prophylactic technique for PJK. 


\section{Junctional zone linear regression analysis}

A number of studies have suggested means to attain a "gradual" transition in ROM in the junctional zone. However, no hypothesis on the optimal transition zone had been formulated yet. In an effort to provide a quantitative comparison, a linear regression analysis over ROMs from the index-1 segment up to the first uninstrumented segment (index +1 or index +2 ) was performed in the present study. The $\mathrm{R}^{2}$-values of each semirigid junctional fixation technique suggested a high linear correlation between instrumented level and ROM. This overall high $\mathrm{R}^{2}$-value is inherent to the analysis as the normalized motion is $\sim 0.0$ at the PSF and $\sim 1.0$ at the first level proximal to the instrumentation. The transverse process hook group had the highest $\mathrm{R}^{2}$-value for one-level semirigid junctional fixation techniques, indicating the most linear transition zone possibly resulting in the best distribution of stress over the UIV and UIV+1 vertebrae. The $\mathrm{R}^{2}$-Values for knotted sublaminar tape were higher compared with clamped sublaminar tape for one- and two-level fixation techniques, also indicating a more gradual transition. Finally, the two-level clamped sublaminar tape group had an $\mathrm{R}^{2}$-value similar to regular PSF, indicating that the two-level fixation provides no added benefit over one-level fixation. Although directly comparing the $\mathrm{R}^{2}$ values is of limited statistical strength, together with the ROM analysis at individual levels, this analysis gives a clear indication that these techniques result in biomechanically distinct transition zones.

$N Z$

Another indication for an optimal transition zone may be found when evaluating the effects of various instrumentation techniques on the NZ, defined as the unforced movement around the neutral position of the spine. In light of degenerative lumbar disc diseases, Panjabi et al. postulated that a slimmer NZ is indicative of a more stable spine, whereas a wide NZ is believed to be associated with pain [33]. This perception led to the introduction of dynamic lumbar stabilization systems to reduce lower back pain [6,34]. Semirigid junctional fixation for thoracolumbar spinal surgery aims at creating a ROM transition zone between the rigid PSF and the proximally uninstrumented spine. This does not necessarily imply that a semirigid junctional fixation should alter the NZ. In contrast to knotted sublaminar tape and TPHs, the NZ of clamped tape was diminished at the index level in the present study. The limited rotational freedom of the vertebrae with respect to the TPHs and unconstrained sliding of the knotted sublaminar tape with respect to the rods possibly facilitate this phenomenon. Ultimately, this might translate into lower general stresses when using TPHs and knotted sublaminar tape, but the lack of additional measurement, for example, intradiscal pressure measurements, restricts us from further differentiating between the sublaminar fixation techniques.

\section{Study considerations}

Although the present study has quantitatively characterized the transition zone, it remains unclear how biomechanical findings translate into clinical complication rates. We have hypothesized that a linear ROM transition over the junctional zone is ideal, as this seems very intuitive for a two motion segment junctional zone. However, this may not be the case, especially for a three motion segment junctional zone. Comparable studies have utilized IDP measurements to obtain an indication of the stresses generated within the vertebrae after spinal fusion [20,21]. Comparing the same techniques evaluated in this study in a finite element model could provide insight into the stresses within the different vertebral elements and ligamentous structures [35]. This could provide us with a better understanding of the interplay between instrumentation and the stresses acting upon the vertebral elements. Assuming that lower peak forces in the vertebral bodies would result in a lower incidence of PJK and PJF, a clear advice regarding the optimal technique for semirigid junctional fixation could then be postulated.

It must also be noted that the number of techniques that could be compared was limited. Two level instrumentation with TPH was not performed as we deemed this condition clinically irrelevant. We presume that such a construct would also just shift the junctional zone proximally, similar to the two-level clamped sublaminar tape condition. Additionally, the use of tapered rods and low stiffness rods were considered as alternative techniques to provide a semirigid junctional fixation. However, previous studies on low stiffness rods and tapered rods demonstrated limited biomechanical effectiveness [21,23]. Further expansion of the experiment could also be detrimental to the cadaveric specimens, therefore we decided to omit these conditions. Finally, reinforcement of the anterior column using prophylactic vertebroplasty is also of clinical interest. Previously, a study in which one- and two-level vertebroplasty supraadjacent to PSF was compared with standard PSF in an ex vivo human cadaveric experiment [36]. This study demonstrated a lower incidence of vertebral fractures after the specimens were subjected to eccentric compressive loading when the specimen were reinforced with two-level prophylactic vertebroplasty. The effects of vertebroplasty are limited to increasing the strength and stiffness of bony elements, whereas semirigid fixation supports the soft tissues of the spine and directly affects spinal kinematics. Thus, direct comparison between these types of techniques in a quasistatic experimental setup with motion parameters as the sole outcome would not provide a fair comparison.

This study has certain limitations inherent to ex vivo cadaveric biomechanical studies. First, the repetitive testing and absence of randomization in the test sequence may have potentially biased the results. A strictly defined test sequence was followed in order to keep the posterior ligamentous complex functional throughout the experiment as 
long as possible. Since ligamentous resection was necessary for sublaminar tape insertion, the native condition at the start and at the end of a test sequence could not be completely compared with elucidate any temporal changes in specimen mechanical properties. However, comparing the ROM of the uninstrumented segments (L2-L3 and T8 -T9) in the native condition to the experimental conditions did not reveal significant differences. The absence of significant differences in these levels indicates that no temporal effects have influenced the results and the repetitive testing may only have limited effects on the results.

Strikingly, most tests resulted in an increased ROM proximal to the upper instrumented vertebrae. Viswanathan et al. have demonstrated similar effects, but did not address these findings [20]. We believe that the increased ROM could be due to two effects: first, the ligament resection may result in relaxation of the ligamentous structures, spanning multiple levels, and thus the biomechanics may be affected beyond the instrumented segments. Second, the overall biomechanics may change due to the PSF, and thus the overall applied moment could shift locally, to produce impure moments and possibly a force vector.

The donors of the present study were of a relatively high average age compared with similar studies. This may have affected the average degree of intervertebral disc degeneration and bone mineral density, although the bone mineral density was within the normal population range [37]. The disc status may have influenced the overall flexibility of the spines, but all results were normalized to the native spine. Hence, specimen specific effects were reduced as much as possible. Keeping the intended population with a degenerated spine in mind, we expect that this has only limited effects on the generalization of the results of this study.

Finally, the question remains how the initial biomechanical effects demonstrated in the present study translate into the long-term, considering that the intended outcome of the surgical procedure is spinal fusion. Clinically, the majority of PJK is known to develop in the first 6 months postoperatively [5]. Bone apposition associated with the spinal fusion process, vertebral bone remodeling and soft-tissue adaptation are ongoing during this period, but since these processes typically take much longer than 6 months, the initial fixation characteristics of the semirigid instrumentation appear to play an essential role in the development of PJK. The effects demonstrated in the present study are thus only reflective of the short-term postoperative situation. The aforementioned biological processes will definitely affect in vivo spinal biomechanics, but due to the limitations of ex vivo biomechanical testing, we cannot expound on this.

\section{Conclusions}

In the quest for effective means to reduce the incidence of instrumentation related complications after long-segment instrumented spinal fusion, we have demonstrated ex vivo that TPHs, one-level clamped sublaminar tape, and one- or two-level knotted sublaminar tape all generate a more gradual transition of ROM in the junctional zone. Knotted sublaminar tape appears to be capable of extending the junctional zone over two motion segments, whereas twolevel clamped sublaminar tape seems to shift the junction by a single level. TPH and knotted sublaminar tapes are capable of maintaining a more physiological neutral zone compared with clamped sublaminar tape. Well-designed clinical studies are required to relate biomechanical findings to clinical effectiveness and thus further elucidate the relationship between spine biomechanics and the risk of PJK and PJF after long-segment instrumented spinal fusion.

\section{Acknowledgments}

The authors would like to acknowledge Theo Smit, Rob de Bie and Sander van Kuijk for their valuable input and help with interpretation of the results and thank Eva Jacobs for critically reviewing the manuscript.

\section{Supplementary materials}

Supplementary material associated with this article can be found in the online version at https://doi.org/10.1016/j. spinee.2021.01.017.

\section{References}

[1] Sciubba DM, Yurter A, Smith JS, Kelly MP, Scheer JK, Goodwin $\mathrm{CR}$, et al. International Spine Study Group. A comprehensive review of complication rates after surgery for adult deformity: a reference for informed consent. Spine Deform 2015;3(6):575-94.

[2] Kim HJ, Lenke LG, Shaffrey CI, Van Alstyne EM, Skelly AC. Proximal junctional kyphosis as a distinct form of adjacent segment pathology after spinal deformity surgery: a systematic review. Spine (Phila Pa 1976) 2012;37(22 Suppl):S144-64.

[3] DeWald CJ, Stanley T. Instrumentation-related complications of multilevel fusions for adult spinal deformity patients over age 65: surgical considerations and treatment options in patients with poor bone quality. Spine (Phila Pa 1976) 2006;31(19 Suppl):S144-51.

[4] Glattes RC, Bridwell KH, Lenke LG, Kim YJ, Rinella A, Edwards 2nd C. Proximal junctional kyphosis in adult spinal deformity following long instrumented posterior spinal fusion: incidence, outcomes, and risk factor analysis. Spine (Phila Pa 1976) 2005;30(14):1643-9.

[5] Lau D, Clark AJ, Scheer JK, Daubs MD, Coe JD, Paonessa KJ, et al. SRS Adult Spinal Deformity Committee. Proximal junctional kyphosis and failure after spinal deformity surgery: a systematic review of the literature as a background to classification development. Spine (Phila Pa 1976) 2014;39(25):2093-102.

[6] Hyun SJ, Lee BH, Park JH, Kim KJ, Jahng TA, Kim HJ. Proximal junctional kyphosis and proximal junctional failure following adult spinal deformity surgery. Korean J Spine 2017;14(4):126-32.

[7] Liu FY, Wang T, Yang SD, Wang H, Yang DL, Ding WY. Incidence and risk factors for proximal junctional kyphosis: a meta-analysis. Eur Spine J 2016;25(8):2376-83.

[8] O'Leary PT, Bridwell KH, Lenke LG, et al. Risk factors and outcomes for catastrophic failures at the top of long pedicle screw constructs: a matched cohort analysis performed at a single center. Spine (Phila Pa 1976) 2009;34(20):2134-9.

[9] Kim DK, Kim JY, Kim DY, Rhim SC, Yoon SH. Risk factors of proximal junctional kyphosis after multilevel fusion surgery: more than 2 years follow-up data. J Korean Neurosurg Soc 2017;60 (2):174-80. 
[10] Diebo BG, Jalai CM, Challier V, Marascalchi BJ, Horn SR, Poorman $\mathrm{GW}$, et al. Novel index to quantify the risk of surgery in the setting of adult spinal deformity: a study on 10,912 patients from the nationwide inpatient sample. Clin Spine Surg 2017;30(7):E993-9.

[11] Park SJ, Lee CS, Chung SS, Lee JY, Kang SS, Park SH. Different risk factors of proximal junctional kyphosis and proximal junctional failure following long instrumented fusion to the sacrum for adult spinal deformity: survivorship analysis of 160 patients. Neurosurgery 2017;80(2):279-86.

[12] Kim HJ, Bridwell KH, Lenke LG, Park MS, Song KS, Piyaskulkaew $\mathrm{C}$, et al. Patients with proximal junctional kyphosis requiring revision surgery have higher postoperative lumbar lordosis and larger sagittal balance corrections. Spine (Phila Pa 1976) 2014;39(9):E576-80.

[13] Kim YJ, Bridwell KH, Lenke LG, Kim J, Cho SK. Proximal junctional kyphosis in adolescent idiopathic scoliosis following segmental posterior spinal instrumentation and fusion: minimum 5-year followup. Spine (Phila Pa 1976) 2005;30(18):2045-50.

[14] Kim YJ, Lenke LG, Bridwell KH, Kim J, Cho SK, Cheh G, et al. Proximal junctional kyphosis in adolescent idiopathic scoliosis after 3 different types of posterior segmental spinal instrumentation and fusions: incidence and risk factor analysis of 410 cases. Spine (Phila Pa 1976) 2007;32(24):2731-8.

[15] Hassanzadeh H, Gupta S, Jain A, El Dafrawy MH, Skolasky RL, Kebaish KM. Type of anchor at the proximal fusion level has a significant effect on the incidence of proximal junctional kyphosis and outcome in adults after long posterior spinal fusion. Spine Deform 2013;1(4):299-305.

[16] Line BG, Bess S, Lafage R, Lafage V, Schwab F, Ames C, et al. International Spine Study Group. Effective prevention of proximal junctional failure in adult spinal deformity surgery requires a combination of surgical implant prophylaxis and avoidance of sagittal alignment overcorrection. Spine (Phila Pa 1976) 2020;45(4):258-67.

[17] Viswanathan VK, Kukreja S, Minnema AJ, Farhadi HF. Prospective assessment of the safety and early outcomes of sublaminar band placement for the prevention of proximal junctional kyphosis. J Neurosurg Spine 2018;28(5):520-31.

[18] Matsumura A, Namikawa T, Kato M, Oyama S, Hori Y, Yabu A, et al. Effect of different types of upper instrumented vertebrae instruments on proximal junctional kyphosis following adult spinal deformity surgery: pedicle screw versus transverse process hook. Asian Spine J 2018;12(4):622-31.

[19] Safaee MM, Deviren V, Dalle Ore C, Scheer JK, Lau D, Osoriao JA, et al. Ligament augmentation for prevention of proximal junctional kyphosis and proximal junctional failure in adult spinal deformity. $\mathrm{J}$ Neurosurg Spine 2018;28(5):512-9.

[20] Viswanathan VK, Ganguly R, Minnema AJ, DeVries Watson NA, Grosland NM, Fredericks DC, et al. Biomechanical assessment of proximal junctional semi-rigid fixation in long-segment thoracolumbar constructs. J Neurosurg Spine 2018;30(2):184-92.

[21] Facchinello Y, Brailovski V, Petit Y, Brummund M, Tremblay J, MacThiong JM. Biomechanical assessment of the stabilization capacity of monolithic spinal rods with different flexural stiffness and anchoring arrangement. Clin Biomech (Bristol, Avon) 2015;30(10):1026-35.

[22] Thawrani DP, Glos DL, Coombs MT, Bylski-Austrow DI, Sturm PF. Transverse process hooks at upper instrumented vertebra provide more gradual motion transition than pedicle screws. Spine (Phila Pa 1976) 2014;39(14):E826-32.

[23] Lange T, Schmoelz W, Gosheger G, Eichinger M, Heinrichs CH, Boevingloh AS, et al. Is a gradual reduction of stiffness on top of posterior instrumentation possible with a suitable proximal implant? A biomechanical study. Spine J 2017;17(8):1148-55.

[24] Ogawa H, Hori H, Oshita H, Akaike A, Koyama Y, Shimizu T, et al. Sublaminar wiring stabilization to prevent adjacent segment degeneration after lumbar spinal fusion. Arch Orthop Trauma Surg 2009;129 (7):873-8.

[25] Tachibana N, Kawamura N, Kobayashi D, Shimizu T, Sasagawa T, Masuyama S, et al. Preventive effect of dynamic stabilization against adjacent segment degeneration after posterior lumbar interbody fusion. Spine (Phila Pa 1976) 2017;42(1):25-32.

[26] Roth AK, van der Veen AJ, Bogie R, Willems PC, van Rietbergen B, van Rhijn LW, et al. Range of motion in segmental versus nonsegmental ultrahigh molecular weight polyethylene sublaminar wire growth guidance type constructs for early-onset scoliosis correction. Spine (Phila Pa 1976) 2015;40(23):E1212-8.

[27] Fujita M, Diab M, Xu Z, Puttlitz CM. A biomechanical analysis of sublaminar and subtransverse process fixation using metal wires and polyethylene cables. Spine (Phila Pa 1976) 2006;31(19): $2202-8$.

[28] Griffith JF, Wang YX, Antonio GE, Choi KC, Yu A, Ahuja AT, et al. Modified Pfirmann grading system for lumbar intervertebral disc degeneration. Spine (Phila Pa 1976) 2007;32(24):E708-12.

[29] Bogie R, Roth AK, de Faber S, de Jong JJ, Welting TJ, Willems PC, et al. Novel radiopaque ultrahigh molecular weight polyethylene sublaminar wires in a growth-guidance system for the treatment of earlyonset scoliosis: feasibility in a large animal study. Spine (Phila Pa 1976) 2014;39(25):E1503-9.

[30] Mannen EM, Ranu SS, Villanueva AM, Friis EA. Validation of a novel spine test machine. J Med Devices 2015;9(1):MED-14-1137.

[31] Smit TH, van Tunen MS, van der Veen AJ, Kingma I, van Dieen JH. Quantifying intervertebral disc mechanics: a new definition of the neutral zone. BMC Musculoskelet Disord 2011;12:38.

[32] Hohn EA, Chu B, Martin A, Yu E, Telles C, Leasure J, et al. The pedicles are not the densest regions of the lumbar vertebrae: implications for bone quality assessment and surgical treatment strategy. Global Spine J 2017;7(6):567-71.

[33] Panjabi MM. The stabilizing system of the spine. Part II. Neutral zone and instability hypothesis. J Spinal Disord 1992;5(4):390-6. discussion 7.

[34] Graf H. Lumbar instability. Surgical treatment without fusion. Rachis 1992;412:123-37

[35] Bess S, Harris JE, Turner AW, Lafage V, Smith JS, Shaffrey CI, et al. The effect of posterior polyester tethers on the biomechanics of proximal junctional kyphosis: a finite element analysis. J Neurosurg Spine 2017;26(1):125-33.

[36] Kebaish KM, Martin CT, O’Brien JR, LaMotta IE, Voros GD, Belkoff SM. Use of vertebroplasty to prevent proximal junctional fractures in adult deformity surgery: a biomechanical cadaveric study. Spine J 2013;13(12): 1897-903.

[37] Raffat SK, Shaikh AB, Sarim M, Syed AR. Bone mineral density comparison of total body, lumbar and thoracic: an exploratory study. J Pak Med Assoc 2015;65(4):388-91. 